suggests that discontinuation of bDMARD should be considered in patients on cDMARD therapy, fulfilling the more stringent remission criteria by CDAI. Disclosure of Interest: None declared

DOI: 10.1136/annrheumdis-2018-eular.3764

\section{THU0221 CLINICAL OUTCOMES OF ABATACEPT VERSUS TNF INHIBITORS IN ACPA-POSITIVE PATIENTS WITH RHEUMATOID ARTHRITIS: DATA FROM THE BIOLOGIC REGISTER KOBIO}

S.-K. Lee ${ }^{1}$, S. Oh ${ }^{2}$, H.-A. Kim ${ }^{3}$, Y.-B. Park ${ }^{4}$, S.-S. Lee ${ }^{5}$, K. Shin ${ }^{1} .{ }^{1}$ Division of Rheumatology, ${ }^{2}$ Department of Biostatistics, Seoul Metropolitan GovernmentSeoul National University Hospital Boramae Medical Center, Seoul; ${ }^{3}$ Division of Rheumatology, Ajou University School of Medicine, Suwon; ${ }^{4}$ Division of Rheumatology, Yonsei University College of Medicine, Seoul; ${ }^{5}$ Division of Rheumatology, Chonnam University Hospital, Gwangju, Korea, Republic of Ireland

Background: Determining the optimal, patient-tailored biologic agent is a new challenge for future guidelines in rheumatoid arthritis (RA) management. Recent studies demonstrated that anti-citrullinated protein antibody (ACPA) -positive patients have better disease activity improvement with abatacept (ABA), yet validation studies are in need.

Objectives: To investigate disease activity changes after treatment with $A B A$ versus TNF inhibitors (TNFi) in Korean ACPA-positive, RA patients.

Methods: Data of RA patients were obtained from the Korean College of Rheumatology Biologics Registry (KOBIO). ACPA-positive patients who were treated with $\mathrm{ABA}$ and TNFi were selected through propensity score matching (1:2, calliper $=0.2 * S D$ ). Clinical outcomes including CDAl changes at the first year of therapy were evaluated, and adjusted drug survival in each group was analysed.

Results: The baseline characteristics of the ABA $(n=97)$ and TNFi $(n=194)$ groups were comparable. The CDAI reduction after 1 year treatment was significant in the ABA group compared with patients who received TNFi ( -16.78 versus $-13.61, p=0.0198$ ) [figure 1]. This was confined when used as the first-line agent $(p=0.0213)$. Proportion of remission and low disease activity in ABA was significant as well $(p=0.041)$. Patients with the lower tertile of ACPA titers treated with $A B A$ had the most significant CDAl reduction compared with the TNFi group $(p=0.0201)$. Drug retention rate (median follow-up 48 months) of ACPA-positive ABA users was also notable compared with TNFi yet did not meet statistical significance (adjusted hazard ratio $0.774, \mathrm{p}=0.086$ )
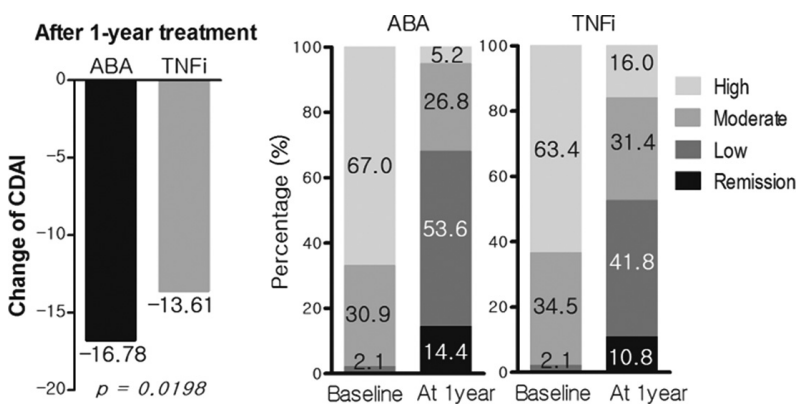

Conclusions: Our data further support that ACPA could also be an important marker to help determine first-line biologic agent of choice among the armamentarium of biologic therapy for RA patients.

Acknowledgements: We would like to thank Song Wha Chae and Evo Alemao for their input and support.

Disclosure of Interest: None declared

DOI: 10.1136/annrheumdis-2018-eular.4357

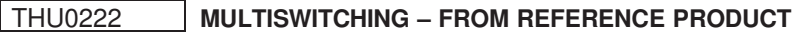 ETANERCEPT TO BIOSIMILAR AND BACK AGAIN - REAL-WORLD DATA FROM A CLINIC-WIDE MULTISWITCH EXPERIENCE}

V. Sigurdardottir, A. Svärd. Center for Clinical Research Dalarna, Falun, Sweden

Background: The etanercept (ETN) biosimilar SB4 was introduced in Sweden in 2016 at a lower price than the reference product etanercept (RPE). Now the reverse is true, as the price of RPE dropped. Switching ETN-treated patients to the lowest priced ETN available is economically favourable. The safety of multiple switches between RPE and biosimilar has been adressed in a psoriasis trial(, ${ }^{1}$ finding no indications of harm. No reports on outcomes of multiswitching in a rheumatology setting are available.
Objectives: To describe the impact of a clinic-wide switch from RPE to SB4 and then back to RPE on disease activity and drug-survival, relating outcomes to a historical cohort of RPE-treated patients.

Methods: Observational study of 145 patients switched from RPE to SB4 (day $0=20 / 4 / 2016$ ) and back to RPE (day $544=16 / 10 / 2017$ ) for economical reasons. Letters were mailed to patients on day 0 and 544, informing them that prescriptions had been changed from RPE to SB4 and from SB4 to $\mathrm{RPE}$ respectively. During days $1-543$, clinicians were allowed to switch patients back to RPE if requested by the patient or if medically indicated. Disease activity data was entered into the Swedish Rheumatology Quality Register (SRQ) at visits. The SRQ was searched retrospectively for data from day -365 to 771 (May 31, 2018). Visits were categorised into visits occurring a) on days -365 to day 0 , b) on days 1-543 and c) on days 544771. A reference cohort of all RPE-treated patients on April 20, 2013 at the clinic was used for comparison.

Results: Numbers and proportions of patients discontinuing SB4 during days $1-543$ in the switching cohort and RPE in the historical cohort are shown in the table 1. On day 544, the 97 patients still treated with SB4 were switched back to RPE. In the switching cohort, DAS28 and CRP did not change significantly when comparing data from visits occurring before the switch from RPE to SB4 to data from visits that occurred on days 1-543 and days 544-636 (fig ure 1). Data from 5 months of additional follow-up, up until day 771 will be presented at the congress. Among the 24 patients that discontinued SB4 during days 1-543 and went back to RPE, no worsening of disease activity parameters was seen during SB4 treatment.

\begin{tabular}{lccc}
\hline & $\begin{array}{c}\text { Switching cohort, } \\
\mathbf{n}=\mathbf{1 4 5}\end{array}$ & $\begin{array}{c}\text { Historical RPE-treated } \\
\text { cohort, } \mathbf{n = 9 8}\end{array}$ & $\mathbf{p}$ \\
\hline $\begin{array}{l}\text { Disontinued SB4/RPE, } \\
\text { total }\end{array}$ & $48(33)$ & $15(15)$ & 0.002 \\
\$Back to RPE & $24(17)$ & Not applicable & N/A \\
$\begin{array}{l}\text { No biologic } \\
\text { \$Non ETN biologic }\end{array}$ & $14(10)$ & $6(6)$ & 0.32 \\
$\begin{array}{l}\text { On ETN (SB4 or RPE) at } \\
\text { day 544 }\end{array}$ & $10(7)$ & $9(9)$ & 0.52 \\
& $121(83)$ & $83(85)$ & 0.80 \\
\end{tabular}

*During days $1-543$ \$ Treatment after discontinuation of SB4/RPE

DAS28, means $\pm 95 \% \mathrm{Cl}$

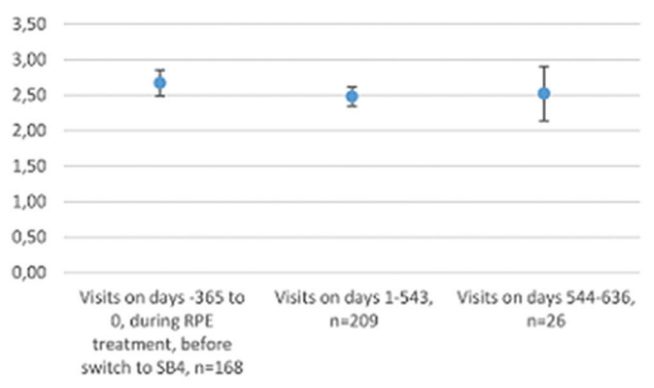

hs-CRP mg/L, means $\pm 95 \% \mathrm{Cl}$

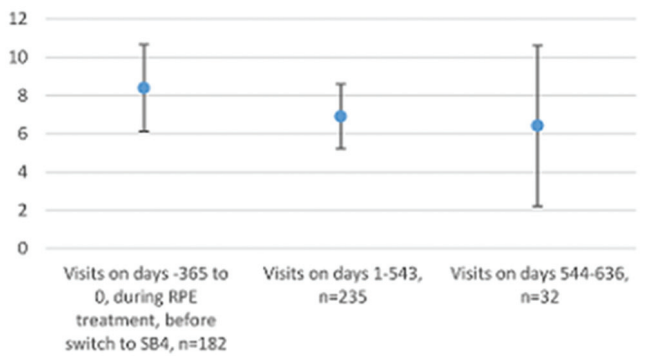

Abstract THU0222 - Figure 1. Mean DAS28 and CRP with $95 \% \mathrm{Cl}$ for 145 patients in the switching cohort according to timepoint of visit..n:s refer to number of visits contributing to data during each period.

Conclusions: The strategy of multiswitching ETN-treated patients has thus far not impacted disease activity negatively in our population. An additional 5 months of follow-up data after the second switch will be presented at the congress. A high proportion of patients discontinued SB4 after the initial switch, as no worsening in disease activity measures was seen in the data we believe this to have been due to nocebo effects. 


\section{REFERENCE:}

[1] Gerdes S, Thaci D, Griffiths CEM, Arenberger P, Poetzl J, Wuerth G, et al. Multiple switches between GP2015, an etanercept biosimilar, with originator product do not impact efficacy, safety and immunogenicity in patients with chronic plaque-type psoriasis: 30 -week results from the phase 3, confirmatory EGALITY study. Journal of the European Academy of Dermatology and Venereology: JEADV 2017.

Disclosure of Interest: None declared

DOI: 10.1136/annrheumdis-2018-eular.2769

\begin{tabular}{l|l}
\hline THU0223 & IMPACT OF TREATMENT IN PATIENTS WITH \\
& RHEUMATOID ARTHRITIS AND DEPRESSIVE \\
& SYMPTOMS IN THE MONARCH PHASE 3 TRIAL OF \\
& SARILUMAB
\end{tabular}

V. Strand ${ }^{1}$, O. Hagino ${ }^{2}$, S. Guillonneau ${ }^{3}$, S. Boklage ${ }^{4}$, M. Reaney ${ }^{5}$, J. Sadeh ${ }^{2}$, N. Narcisse ${ }^{6}$, E. Mangan ${ }^{4}$, T. Kimura ${ }^{4} .{ }^{1}$ Stanford University, Palo Alto; ${ }^{2}$ Sanofi, Bridgewater, USA; ${ }^{3}$ Sanofi, Chilly-Mazarin, France; ${ }^{4}$ Regeneron Pharmaceuticals, Inc., Tarrytown, USA; ${ }^{5}$ Sanofi, Guildford, UK; ${ }^{6}$ AIXIAL, Boulogne-Billancourt, France

Background: In the MONARCH Phase 3 randomised controlled trial (RCT) [NCT02332590], sarilumab subcutaneous (SC) $200 \mathrm{mg}$ every 2 weeks (q2w) improved clinical outcomes and multiple aspects of health status/health-related quality of life (HRQoL), as measured by the Medical Outcomes Survey Short Form (SF-36) questionnaire, to levels greater than adalimumab SC $40 \mathrm{mg} \mathrm{q2w.}$ Both treatments were administered as monotherapy in patients with active rheumatoid arthritis (RA) who had discontinued treatment with methotrexate. Depression/mood disorder is a common co-morbidity in people with RA.

Objectives: To explore whether observed differences in health status/HRQoL following treatment with sarilumab compared with adalimumab are also seen in the subgroup of patients in the MONARCH trial with probable depressive symptoms. Methods : Post-hoc statistical analyses were performed. Patients were categorised as having probable major depressive disorder ${ }^{1}$ (PMDD; SF-36 mental health $(\mathrm{MH})$ domain score $\leq 56$ ) or probable depressed mood and anhedonia ${ }^{2}$ (PDMA; score $\leq 10$ on both items of the MH domain: "Have You Felt Downhearted and Depressed" and "Have You Felt So down in the Dumps that nothing could cheer you up"). Least squares mean (LSM) differences in changes from baseline (CFB) in SF-36 domains at Week 24 were calculated for sarilumab PMDD/PDMA versus adalimumab PMDD/PDMA. Sensitivity analysis included adjustment for Disease Activity Score 28 C-reactive protein (DAS28-CRP) at baseline.

Results: Of the 369 patients from MONARCH, 250 (67.78\%) were categorised with PMDD (mean age 52 years, 85\% female) and 194 (52.6\%) with PDMA (mean age 52 years, $87 \%$ female). Disease duration, DAS-28 CRP, tender and swollen joint counts (table 1) and SF-36 domain scores (figure 1) were similar between sarilumab and adalimumab within the PMDD and PDMA subpopulations at baseline. LSM differences in CFB in SF-36 domains were greater for sarilumab versus adalimumab at Week 24 in physical functioning (PF), bodily pain (BP), vitality (VT) and social functioning (SF) domains in both the PMDD and PDMA subgroups, and role-physical $(R P)$ in the PMDD subgroup (nominal $p<0.05$ ) (figure 1). Sensitivity analysis showed similar results.

Abstract THU0223 - Table 1

\begin{tabular}{|c|c|c|c|c|}
\hline \multicolumn{5}{|l|}{ Table } \\
\hline \multirow[t]{2}{*}{$\begin{array}{l}\text { Baseline characteristics in } \\
\text { MONARCH patients with PMDD or } \\
\text { POMAA }\end{array}$} & \multicolumn{2}{|c|}{$\begin{array}{l}\text { PMDD: } \\
\text { SF-36 } \\
\text { domain score }<=56 \\
\text { (N=250) }\end{array}$} & \multicolumn{2}{|c|}{$\begin{array}{l}\text { PDMA: } \\
\text { s10 on both items of } 5 \text { FF-36 MH domain } \\
(N=194)\end{array}$} \\
\hline & $\begin{array}{l}\text { Sarilumab } \\
\text { 200mg q2w (n=128) }\end{array}$ & $\begin{array}{l}\text { Adalilimumab } \\
\text { 40 mg q2w (n=132) }\end{array}$ & $\begin{array}{l}\text { Sarilumab } \\
\text { 200mg 22w (n=98) }\end{array}$ & $\begin{array}{l}\text { Adalimumab } \\
\text { 40m q2w } \\
(n=96)\end{array}$ \\
\hline \begin{tabular}{|l}
$\begin{array}{l}\text { Duration of RA since diagnosis, } \\
\text { vears, mean (SD) }\end{array}$ \\
\end{tabular} & $8.29(8.13)$ & $7.03(8.53)$ & $7.92(7.30)$ & $7.46(8.49)$ \\
\hline DAS28-CRP, mean (SO) & $6.13(0.85)$ & $6.18(0.88)$ & $6.17(0.96)$ & $6.18(0.83)$ \\
\hline Tender joint count $(0-68)$, mean (SD) & $29.03(14.05)$ & $28.36(14.21)$ & $28.98(14.34)$ & $28.69(14.46)$ \\
\hline Swollen joint count $(0-66)$, mean (SD) & $19.20(11.67)$ & $18.69(10.74)$ & $19.68(11.78)$ & $19.53(11.09)$ \\
\hline
\end{tabular}

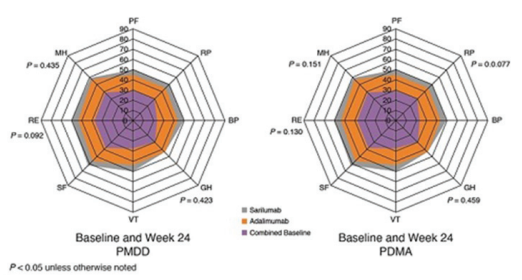

Conclusions: Among patients with RA and probable depressive symptoms, sarilumab SC 200 mg q2w monotherapy was more effective than adalimumab SC $40 \mathrm{mg}$ q2w monotherapy in demonstrating clinically meaningful improvements in some domains of health status/HRQoL. This may be a function of the different target of sarilumab (soluble IL-6 receptor [sIL-6R]) and associated improvements in disease activity versus adalimumab (tumour necrosis factor [TNF $\alpha$ ]).

\section{REFERENCES:}

[1] Matcham, et al. BMC Musculoskeletal Disorders 2016;17:224.

[2] Sun Y, et al. EULAR Congress 2017; June 14-17 2017; Madrid, Spain.

Acknowledgements: Research sponsored by Sanofi and Regeneron Pharmaceuticals, Inc.

Disclosure of Interest: V. Strand Consultant for: AbbVie, Amgen, AstraZeneca, Bayer, Boehringer Ingelheim, Celltrion, Corrona, Crescendo Bioscience, Eli Lilly Genentech/Roche, GlaxoSmithKline, Horizon, Janssen, Merck, Novartis, Pfizer, Regeneron Pharmaceuticals, Samsung, Sandoz, Sanofi and UCB, O. Hagino Shareholder of: Sanofi, Employee of: Sanofi, S. Guillonneau Shareholder of: Sanofi, Employee of: Sanofi, S. Boklage Shareholder of: Regeneron Pharmaceuticals, Inc., Employee of: Regeneron Pharmaceuticals, Inc., M. Reaney Share holder of: Sanofi, Employee of: Sanofi, J. Sadeh Shareholder of: Sanofi, Employee of: Sanofi, N. Narcisse Consultant for: Sanofi, E. Mangan Shareholder of: Regeneron Pharmaceuticals, Inc., Employee of: Regeneron Pharmaceuticals, Inc., T. Kimura Shareholder of: Regeneron Pharmaceuticals, Inc., Employee of: Regeneron Pharmaceuticals, Inc.

DOI: 10.1136/annrheumdis-2018-eular.3714

\section{THU0224 RENACER STUDY: EFFICACY AND SAFETY ASSESSMENT OF CZP THERAPY IN THE TREATMENT OF 501 PATIENTS WITH RHEUMATOID ARTHRITIS(RA) AMONG SPANISH POPULATION IN CLINICAL PRACTICE}

V. Torrente-Segarra ${ }^{1}$, M. Fernandez ${ }^{2}$, R. Expósito ${ }^{3}$, N.P. Garrido ${ }^{4}$, A. SanchezAndrade $^{5}$, J.R. Lamua ${ }^{6}$, A. Olivé ${ }^{7}$, J.V. Tovar ${ }^{8}$, on behalf of On behalf of RENACER Study Group. ${ }^{1}$ Rheumatology, Hospital General Hospitalet-Moisès Broggi, Hospitalet Llobregat, ${ }^{2}$ Rheumatology, Hospital Universitario de Guadalajara, Guadalajara; ${ }^{3}$ Rheumatology, Hospital Comarcal de Laredo, Laredo; ${ }^{4}$ Rheumatology, Hospital Universitario Virgen del Rocío, Sevilla; ${ }^{5}$ Rheumatology, Complejo Hospital Universitario Lucus Augusti, Lugo; ${ }^{6}$ Hospital Universitario del Henares, Alcalá de Henares; ${ }^{7}$ Hospital Germans Trias i Pujol, Badalona; ${ }^{8} \mathrm{Hospital}$ General Universitario de Elche, Elche, Spain

Background: Certolizumab PEGol (CZP) differs from other anti-TNFs in that it is monovalent and it lacks the $\mathrm{Fc}$ region found in monoclonal antibodies. CZP is also PEGylated. Its efficacy in patients with rheumatoid arthritis (RA) has been evaluated in previous clinical trials.

Objectives: The purpose of the current study is to assess effectiveness, safety and survival rate in patients with RA after 12 months of treatment and also within specific subgroups, in clinical practice settings.

Methods: Observational longitudinal prospective study of RA patients from 40 sites in Spain. Variables (baseline, 3- and 12 month assessment): socio-demo graphics, smoking status, previous synthetic DMARD (sDMARD) and biological DMARD (bDMARD) use; TJC, SJC, ESR, CRP, DAS28. Response variables EULAR Moderate/Good Response and DAS28 remission and Safety were assessed. Descriptive, comparative and Logistic regression analyses were performed. Kaplan-Meier survival curve was performed.

Results: A total of 501 patients were included: $78.6 \%$ women, mean age 53.6 year $( \pm 13.2 \mathrm{SD})$ and $77 \%$ were aged $<65$ year Mean disease duration 7.5 year $( \pm 7.3 \mathrm{SD})$ and $27.7 \%$ having early RA. Baseline features are shown in table 1. Mean number of prior sDMARD $1.5( \pm 1.1 \mathrm{SD})$. Mean number of prior bDMARD was 0.8 ( \pm 1.2 SD). Mean duration of exposure to CZP was 9.8 months ( \pm 3.4 SD); Concomitant steroids intake $12.6 \%$, sDMARD $24.2 \%$ and sDMARD plus steroids $54.9 \%$; Smoking status: $69.8 \%$ never smoked, $12.9 \%$ former smoker and $17.3 \%$ current smoker.

Baseline predictors of response: lower prior number sDMARD; low number prior bDMARD; higher CRP, ESR, TJC, SJC and DAS28 ( $<<0.05)$ scores.

Patients $<65$ year had shown better DAS28 Remission rates as well as those who had previously received $<2$ sDMARDs, those who were "bionaïve" at CZP initiation and those who used CZP in combination.

CZP survival rates are shown in Figures 1 and 2.

Adverse effects from treatment were reported in 65 patients (13\%), mostly mild

Conclusions: CZP showed benefit in active RA patients, with clear improvement in all clinical parameters, mostly in $<65$ yo patients and those who had received low number of previous sDMARD and bDMARD. Survival rate at 12 month assessment was high, demonstrating a reasonable safety profile.

\section{REFERENCE:}

[1] Torrente-Segarra V, et al; (RENACER StudyGroup). RENACER study: Assessment of 12-month efficacy and safety of 168 certolizumab PEGol rheumatoidarthritis-treated patients from a Spanish multicenter national database. ModRheumatol 2015 Nov 7:1-6. 